\title{
The Influence of Social Media on Buy Decision-making of Young Chinese Consumers
}

\author{
Qi Xiao-lie ${ }^{1}$ \\ ${ }^{1}$ OSEA Alliance Group
}

\begin{abstract}
Social media is playing an increasingly important role in our daily lives. Young Chinese consumers are the primary users of social media in China. Social media is the primary source of information for young Chinese customers, influencing their buying decisions. Through the research obtained three main results: Young Chinese consumers use social media for information. Social media messages are their primary source of information. Social media information influences buy decisions making of young Chinese consumers. Number of negative information on social media moderates the relationships between trust in information of social media and intention to buy
\end{abstract}

\section{INTRODUCTION}

The rapid development of information technology has touched every aspect of our daily life and influenced our consumption habits and buying decisions. The development of social media and the widespread popularity of smartphones in China has led to a considerable change in how we communicate and access information (Wang, 2015). Social media is the primary source of information for consumers. In general, the term "social media" refers to using web-based and mobile communication technologies to accomplish dynamic, interactive communication or dialogue among people (Obar et al., 2015). Our study begins with literature reviews of social media and buys decisions to make a better sense of social media's impact on consumer buy decisions. Next comes the research method, followed by the findings from our exploratory qualitative. Finally, the study will discuss the Limitations of the study and future research.

\section{THEORETICAL LENSES}

\subsection{Social Media}

People use social media for many reasons; the number one reason is connecting and interacting with others. According to Maslow's (1954) Hierarchy of Needs, people want to achieve a sense of belonging through connection with others. After getting physiological and safety needs, people strive to achieve Maslow's third category of needs: a sense of belonging. People can communicate and interact with others through virtual communities on the Internet. Social media has become an avenue for gaining information, knowledge and understanding different viewpoints related to issues, topics, and events. As a form of online media, social media enables participants to have conversations online without communicating with others face to face (Sawyer et al., 2012). Social media is playing an increasingly important role in personal marketing communication (Kietzmannetal, 2011). Take social media as an example. Users communicate and behave pronounced differences between individualistic culture and collectivist culture. Rosen described that groups from an individualistic culture are concerned with meeting new friends and being followed by others rather than maintaining existing social media relationships (2010).

On the other hand, people from collectivist cultures use social media to maintain relationships with relatives or friends instead of developing new social relationships (Rosen, 2010). Kaplan and Haenlein define social media as a set of Internet-based applications built on the foundation of Web 2.0 ideas and technologies to accomplish the creation of self-directed media content (Kaplan \& Haenlein, 2010). Head \& Eisenberg's research shows that social media platforms have become an essential source of information for consumers (2010). Besides, studies have found that college students are the primary social media users to access information. Studies have shown that college students, as social media natives, often use online open resources to access information (Holliday \& Li, 2004). Kim \& Yoo (2014) stated that social media provides new opportunities for consumers to access information. The diffusion of innovation theory explains how new ideas spread within a social organization, with five perceived characteristics: comparative advantage, compatibility, testability, observability, and complexity influencing consumer decision behavior (Alam et al., 2007). The widespread dissemination of social media information has influenced 
individuals to some extent and ultimately contributed to emerging a globally interconnected and mutually understanding society. Many studies have found that social media share the following common characteristics: social media are Web 2.0 applications based on developing the Internet.

Second, the data generated through online interactions is the lifeblood of social media. Third, social media facilitate developing online social networks by linking users' data with other individuals (Obar \& Steven, 2015). Kaplan and Haenlein also proposed different types of social media: collaborative projects, blogs and microblogs, content communities, social networking sites, virtual game worlds, and virtual socials. As technology advances, social media has changed (Kaplan \& Haenlein, 2010). Social media messages are more communicative and flexible than traditional media (Rohm \& Crittenden, 2011). According to Boyd and Ellison (2007), social networking sites allow individuals to create profiles and view others' profiles in the system and make it possible to interact with others in the system. This definition of a social networking site lays the foundation for the functionality of a particular site. Facebook was founded in 2004 by Mark Zuckerberg and had over 800 million users in a global population of 6.9 billion, meaning that one in every 12 people has a Facebook account. YouTube started in 2005 as a video sharing site where users interact with a global online community by watching and sharing video content. Twitter was created in 2006 to deliver real-time information to users.

Social media allows individuals to showcase their websites, products, or services through online social channels. People communicate and exchange ideas online in a way that would have been difficult to imagine in the age of traditional media (Weinberg, 2009, p. 3). Crossregional dialogue, through WeChat, Weibo, QQ, Facebook, YouTube, and Twitter, where information and sharing across geographies, cultures meet daily to provide the most direct information is crucial.

\subsection{Social Media and Consumer Buy Decisions}

Social media not only influences consumer behavior, but it is also an essential factor in the buy decision process (Weinberg, 2009). Two main types of social media influence buying decisions: low-involvement: buy decisions made without planning or thinking ahead vs. high-involvement: buy decisions made after considering various complex factors throughout the decision-making process. Garland summarizes social media's influence on the buy decision process: The problem awareness stage: needs can be triggered by clicking on an ad on a social media page or the "like" button, this feature allows consumers to recognize a potential need. Cognitive needs may be triggered (Galan et al., 2015). Second, information search: searching for information on the Internet or social media to support their buy decision, including online WOM and online social network information (Castronovo \& Huang, 2012). Besides, information gathering can also come from offline information search, which mainly involves consumers' memories of the products or services they have used (Galan et al., 2015). Third, Choice Evaluation Stage: consumers gain valuable information through social media platforms, which provide "unbiased advice" for consumers to compare different options. "(Parker, 2011, p 273). Finally, Buy Decision Stage: during the buy decision stage, consumers evaluate multiple existing consumption decisions and make a final choice among multiple alternatives. During this stage, consumers stop searching and evaluating information and instead focus on making a final choice among multiple alternative buy choices (Cubillo et al., 2006). Furthermore, the post-buy stage is also essential because it can influence consumers' future buy behavior and post-buy reputation (Foxall, 2005).

Social media has become an essential platform for people to interact and communicate with each other and significantly impact consumer buying behaviors and decision-making (Cheung \& Lee, 2010). The interaction between organizations and consumers has also changed. Due to emerging online social media platforms, information access has shifted from companies to consumers (Koufaris et al., 2002). This change suggests that consumers can use positive or negative information disseminated on social media to judge the quality of a company's products or services and thus influence their buying decisions. Social media's influence on consumer behaviors has divided into three categories (Galan et al., 2015): First, the behaviors that influence consumption include positive communication, negative communication, and social media opinion leaders. Second, consumer behaviors are influenced by others, including searching for product information and searching for the opinions of others. Third, consumers use social media as a communication medium to share their post-buy experiences. Another theory related to communication and society can help us understand the impact of social media's widespread use on consumer buy decisions.

Related theories include Media richness theory, Crowd behavior theory, Crowd convergence theory, Conformity theory, and Peer pressure theory. According to media richness theory (Daft \& Lengel, 1984), Kahai and Cooper found that the quality of consumption decisions depends on participants' expertise and recognition of true or false information. In general, content-rich media has a significant positive effect on decision quality when participants' relevant knowledge is high (Kahai \& Cooper, 2003). Social media also creates new peer pressure that is more direct and influential than face-to-face interactions (Power DJ, Phillips-Wren, 2011). Peer pressure refers to the influence that peer groups exert when they encourage an individual to change their attitudes, values, or behaviors (Kandel \& Lazear, 1992). A study by Povo and Phillips found that norm-following can lead to decision making bias as decision-makers are likely to follow norms to gain favor or acceptance from community members (Power DJ, Phillips-Wren, 2011). Levy argues that people in groups behave differently on group behaviors theory, and they know less about the true nature of their behaviors (Levy, 1989). The group convergence theory suggests that group behaviors is not a product of the group itself, but is brought into the group 
by a particular individual. Thus, groups represent a collection of like-minded individuals. In other words, while group behaviors theory argues that groups cause people to act in a certain way, convergence theory argues that people who act in a certain way will come together to form groups. Social media helps people form groups and influence their behaviors (Power DJ \& Phillips-Wren, 2011).

\section{Research Method}

To understand social media's influence on young Chinese customers buys decision-making, we conducted a few indepth interviews. Qualitative research interviews are a method of gaining firsthand information through dialogue. The qualitative approach helps us understand participants' experiences and thoughts and allows interviewers to provide in-depth answers to questions (McNamara, 2007). Glaser and Strauss (1967) initially laid the foundations for Grounded Theory as a qualitative research method following positivism and 'big theory' (Suddaby, 2006). The exploratory qualitative interviews help collect indepth information on social media's impact on individual consumer buy decisions.

As an exploratory qualitative study, we interviewed ten consumers who were University students attending a University in Guangdong province, China. The interviews lasted an average of 2 weeks. The age of the interviewees ranged from 20 to 23 years old. In this study, we focused on the influence of social media on Chinese University students' consumer buy decisions in China. All participants had used social media to support their buy decisions in their daily buy decision-making. We used the same criteria and semi-open-ended questions for all interviewees. We asked the University students on how much social media influenced their buy decisions. We also used the interviews to explore how social media influenced the buy decisions of University student customers. We coded the interviews to explore the role of social media in the buy decision process. Exploratory qualitative research provided us with rich data and presented our findings.

Follow the Grounded Theory; first, we read through all the transcripts of the interview. The first impression from the interviews was that University student consumers rely heavily on social media platforms to get information to support their buy decisions. By rereading the transcripts one by one, we began to label and code the words, phrases, and sentences in the transcripts relevant to the research. During the coding, we tried to stay as close to the data as possible. We selected essential codes and created categories and new codes by merging two or more codes. We discarded some irrelevant early codes to keep the essential codes. Fourth, the categories were tagged to identify the most relevant categories and the connections between them.

The interview aims to understand how social media affects the buy decisions making of university student customers. We conducted the Interviews via WeChat and Tencent meetings, each lasting 45 to 60 minutes. Data analysis consisted of examining recurring themes in the interviewees' responses to the questions.

\section{DISCUSSION AND FINDINGS}

All the respondents who engaged in this study had the experience of using social media to search for information and support their buy decisions. The typical social media software they used were WeChat, Weibo, QQ, and Baidu. Most of the participants used social media multiple times a day. Most of the respondents pointed out (nine out of ten students) that social media and the Internet were their primary channels for news and information.

"Social media is my main channel for communicating with my family, friends, and other people."

Respondents spend anywhere from a few minutes to a few hours a day on social media. Most respondents use their mobile phones to log on to social media to browse information, and they find it easier to $\log$ on to social media platforms with their smartphones. When asked about the primary purpose of using social media, $70 \%$ of the participants answered that using social media makes it easier to communicate with others and access information They also believed that social media helped them to learn and understand unfamiliar quickly. Besides, they used social media to share information, news, photos, and links. Respondents showed that social media played a prominent role in helping them to access information. Besides, postbuy reviews from other buyers it is their primary source of information for buying decisions.

"I search social media information before making a purchasing."

"I will refer to buyer reviews on social media."

"I will compare with online reviews."

"if too much negative information on social media will influence my buy intentions."

Some respondents also said that negative online reviews would affect them more. However, a small amount of negative information would increase their trust in online information.

"If there is too much negative information about a product on social media, it will affect my buying decision."

"Sometimes, a small amount of negative information on social media platforms increases the trust of information."

Social media has become increasingly important in our everyday lives and both advantages and disadvantages of using social media. Social media makes it easy and efficient for us to communicate and interact with people in different parts of the world. Online social media facilitate learning by exchanging messages, sharing links, information. Social media are online platforms to stay socially connected with friends and family and to share information. On the other hand, using social media also has its drawbacks. First, identifying information's authenticity becomes an issue because anyone can post and share personal information on social media, and anyone can browse these sites. More than $50 \%$ of the respondents said (six out of ten students) they do not trust 
the information on social media as businesses may hire people to spread useful information on social media.

"I rarely read online reviews and feel it unreliable.'

"Many social media write fake positive information about their products or services on the platform."

"Many fake reviews on social media nowadays".

Besides, social media creates barriers to everyday communication. Emotions and personal expressions are lost in online communication. Social media leaves less time for face-to-face communication between people.

\subsection{Three key findings emerged from our study:}

- Young Chinese consumers use social media for information. Social media messages are their primary source of information.

- Social media information influences buy decisions making of young Chinese consumers.

- Number of negative information on social media moderates the relationships between trust in information of social media and intention to buy.

\section{LIMITATIONS OF THE STUDY AND FUTURE RESEARCH}

Our following study plans to conduct an online quantitative research survey to validate the hypothesizes. The study plans to questionnaire 300 University student consumers in China to certify our findings. Finally, some limitations to this study. First, our qualitative study conducted in-depth interviews with ten college students in Guangdong, China. Expanding a survey to gain a broader perspective on social media and consumer decisions from other nations or different cultural backgrounds would better understand the relationship between social media use and consumer decisions. The participants' age range could also expand to include a more diverse population, including both older and middle-aged generations in the future study.

\section{ACKNOWLEDGMENT}

Thank you to my wife, Baojun, for putting up with me sitting in my office for hours on end and providing backing and support when needed.

\section{REFERENCES}

1. Alam S S, Khatibi A, Ahmad M I S, et al. Factors affecting e-commerce adoption in the electronic manufacturing companies in Malaysia[J]. International Journal of Commerce and Management, 2007.

2. Boyd DM, Ellison NB. Social network sites: Definition, history, and scholarship $[\mathrm{J}]$. Journal of computer-mediated communication, 2007, 13(1): 210-230.
3. Bulmer D, DiMauro V. 2nd Annual New Symbiosis of Professional Networks study. Retrieved from http://dssresources. com/news/3255. php. 2011.

4. Castronovo C, Huang L. Social media in an alternative marketing communication model. Journal of marketing development and competitiveness. 2012 Feb 1;6(1):117-34.

5. Cheung, Christy MK, and Matthew KO Lee. "A theoretical model of intentional social action in online social networks." Decision support systems 49.1 (2010): 24-30.

6. CNNIC Internet Research. Release of the 43rd CNNIC China Internet Report[J]. China Broadcasting, 2019(4).

7. Cubillo JM, Sánchez J, Cerviño J. International students' decision-making process. International Journal of Educational Management. 2006 Feb 1.

8. Daft RL, Lengel RH. Information richness. A new approach to managerial behavior and organization design. Texas A and M Univ College Station Coll of Business Administration; 1983 May.

9. Fagerstrøm, Asle, Gordon R. Foxall, and Erik Arntzen. "Implications of motivating operations for the functional analysis of consumer choice." Journal of Organizational Behavior Management 30.2 (2010): 110-126.

10. Foxall, Gordon R., and M. Mirella Yani-de-Soriano. "Situational influences on consumers' attitudes and behavior." Journal of Business Research 58.4 (2005): 518-525.

11. Foxall G. Understanding consumer choice. Springer; 2005 Mar 11.

12. Foxall, Gordon R., and M. Mirella Yani-de-Soriano. "Situational influences on consumers' attitudes and behavior." Journal of Business Research 58.4 (2005): 518-525.

13. Foxall, Gordon R., et al. "Consumer behavior analysis and the behavioral perspective model." Management Online Review (MORE) (2011).

14. Galan M, Lawley M, Clements M. Social media's use in postgraduate students' decision-making journey: an exploratory study. Journal of Marketing for Higher Education. 2015 Jul 3;25(2):287-312.

15. Hanna, Richard, Andrew Rohm, and Victoria L. Crittenden. "We're all connected: The power of the social media ecosystem." Business horizons 54.3 (2011): 265-273.

16. Head, A., and Eisenberg, M., 2010. How today's college students use Wikipedia for course-related research. First Monday, 15(3).

17. Holliday, W., and Li, Q., 2004. Understanding the millennials: updating our knowledge about students. Reference services review.

18. Kahai SS, Cooper RB. Exploring the core concepts of media richness theory: The impact of cue multiplicity and feedback immediacy on decision quality. Journal of management information systems. 2003 Jul 1;20(1):263-99. 
19. Kaplan, Andreas M., and Michael Haenlein. "Users of the world, unite! The challenges and opportunities of Social Media." Business horizons 53.1 (2010): 5968.

20. Kietzmann, Jan H., et al. "Social media? Get serious! Understanding the functional building blocks of social media." Business horizons 54.3 (2011): 241251.

21. Kim, K.S., Sin, S.C.J., and Yoo-Lee, E.Y., 2014. Undergraduates' use of social media as information sources.

22. Koufaris, Marios, Ajit Kambil, and Priscilla Ann LaBarbera. "Consumer behavior in web-based commerce: an empirical study." International journal of electronic commerce 6.2 (2001): 115-138.

23. Kandel E, Lazear EP. Peer pressure and partnerships. Journal of Political Economy. 1992 Aug 1;100(4):801-17.

24. Levy L. A study of sports crowd behavior: The case of the great pumpkin incident. Journal of Sport and Social Issues. 1989 Sep;13(2):69-91.

25. McNamara C, Chur-Hansen A, Hay P. Emotional responses to food in adults with an eating disorder: a qualitative exploration[J]. European Eating Disorders Review: The Professional Journal of the Eating Disorders Association, 2008, 16(2): 115-123.

26. Obar, Jonathan A., and Steven S. Wildman. "Social media definition and the governance challenge-an introduction to the special issue." Obar, JA, and Wildman, S.(2015). Social media definition and the governance challenge: An introduction to the special issue. Telecommunications policy 39.9 (2015): 745750.

27. Parker, C. (2011). 301 ways to use social media to boost your marketing. New York: McGraw-Hill.

28. Power DJ, Phillips-Wren G. Impact of social media and Web 2.0 on decision-making. Journal of decision systems. 2011 Jan 1;20(3):249-61.

29. Rosen D, Stefanone M A, Lackaff D. Online and offline social networks: Investigating culturallyspecific behavior and satisfaction[C]//2010 43rd Hawaii International Conference on System Sciences. IEEE, 2010: 1-10.

30. Sawyer R, Chen G M. The impact of social media on intercultural adaptation[J]. 2012.

31. Shaw ME. Group dynamics: The psychology of small group behavior. McGraw-Hill College; 1981.

32. Weinberg, Tamar. "The new community rules: Marketing on the social web." (2009).

33. Zhao S, Grasmuck S, Martin J. Identity construction on Facebook: Digital empowerment in anchored relationships. Computers in human behavior. 2008 Sep 1;24(5):1816-36. 